\title{
DEFINING THE ANTECEDENTS FOR ADOPTION OF RFID IN THE SUPPLY CHAIN
}

\author{
Vic Matta, Ohio University, matta@ohio.edu \\ Chris Moberg, Ohio University, moberg@ohio.edu
}

\begin{abstract}
While the benefits of Radio Frequency Identification (RFID) Technology adoption by organizations within supply chains have regularly been cited in the academic and trade presses, actual adoption has lagged behind early predictions and expectations [9; 18; 33; 41]. One possible explanation for lagging adoption rates may be the relative lack of research on the antecedents of RFID adoption. A thorough review of previous technology adoption research and of RFID research identified four categories of adoption variables. From these categories, four specific variables (top management support, organizational size, expected return on investment, and external pressure from outside forces) are identified as most likely to affect RFID adoption based on their impact on previous technology adoptions and their projected impact on RFID adoption. It is suggested that empirical research on RFID adoption begin with these variables so that support can be provided to increase the adoption of RFID within supply chains.
\end{abstract}

\section{INTRODUCTION}

Like most innovations, applications of Radio Frequency Identification (RFID) Technology began in a specialized field, grew to find applications in indigenous, closed loop scenarios, before eventually realizing its potential in the supply chain sector. RFID is a discontinuous innovation because it not only changes the infrastructure in the adopting firm, it also changes its processes and work flow. The expected improvement in operational efficiencies brought by this technology across the supply chain industry is significant. With the advent of global standards and reduction in tag costs, its adoption should provide many benefits including increased visibility and accuracy, and a reduction in labor costs. On the other hand, there are technological, management, and financial challenges in the implementation of RFID systems which counterbalance its attractiveness. In fact, adoption of RFID by supply chain trading partners has been largely limited to those firms required to do so by a major customer with a strong commitment to RFID, such as Wal-Mart or Best Buy [23]. This makes the adoption of the RFID innovation within supply chains a rich area of study.
This study builds on previous work calling for the development of a research agenda on the adoption of RFID within supply chains so that potential users would have more support to overcome the barriers blocking adoption in many organizations [23]. Matta and Moberg [23] identified two important areas for research: the identification of antecedents significantly related to RFID adoption and empirical research that connected adoption to significant improvements in operational and firm performance. This paper addresses the former research need by developing a model of likely antecedents of RFID adoption that should be examined. While the research on the antecedents of adoption for other technologies such as personal computers, electronic data interchange, and bar codes has been pretty extensive [8; 11; 12; 16; 29; 39], this type of research is currently lacking for RFID adoption in supply chains. The identification of those antecedents more likely to positively affect RFID adoption should guide future researchers to more quickly and effectively demonstrate empirical relationships to support and guide those organizations considering RFID adoption.

In order to identify likely antecedents of RFID adoption, a thorough review of previous technology adoption research within organizations and of qualitative RFID research was conducted. Based on these two research streams, four categories of adoption variables were identified. Each category was evaluated to identify likely antecedents of RFID adoption. This process identified four likely antecedents of RFID adoption requiring further empirical research. This paper will begin with a brief review of the organizational adoption and RFID research streams previously identified. Next, each of the categories of antecedents is thoroughly evaluated for their likely impact on RFID adoption. The paper concludes with a discussion of the proposed RFID adoption model and the need for further research.

\section{PROCESS FOR IDENTIFYING POTENTIAL ANTECEDENTS}

Adoption of IT-based innovation has been studied along many contexts, resulting in a rich body of 
research. Over a hundred antecedents and predictors of adoption have been identified and studied [17]. The dominant model for adoption of technology innovations in these studies has been of the type that posits adoption based on existence of sufficient favorable antecedents in sufficient quantities (See Figure 1).

For example, literature suggests that when a high return on investment is expected, chances of adoption of the innovation are good.

\begin{tabular}{|l|l|}
\hline $\begin{array}{l}\text { One or more } \\
\text { antecedents }\end{array}$ & predict
\end{tabular}$\quad \begin{aligned} & \text { Adoption of } \\
& \text { Innovation }\end{aligned}$

Figure 1: Modified Dominant Model in Adoption [17]

A review of literature on technology adoption reveals a large volume of research conducted on the adoption of many technologies in various industries and settings, and by both individuals and organizations. Because RFID currently has applicability mostly to organizations, the literature review focused mainly on organizational adoption research. Several seminal research studies on the adoption of Information Technology (IT) within organizations were used to identify potential antecedents for RFID adoption. These studies include the Davis' Technology Acceptance Model (TAM1) ,Ventatesh and Davis' TAM2, Rogers' Innovation Diffusion Theory for Organizations, Venkatesh's Unified Theory of Acceptance and Use of Technology, Kwon and Zmud's Diffusion/Implementation Model, and Swanson's Tri-Core Model of Information Systems (IS) Innovations. Some adoption studies have been summative reviews of adoption while others analyzed behavior and reasons for actions such as the Theory of Planned Behavior [1].

An examination of literature on RFID reveals case studies, white papers, and monographs on RFID implementations in several industries and supply chain settings. Also, there is much discussion on the benefits and challenges of RFID adoption. Virtually all such discussion suggests that RFID adoption is lagging behind the expectations, and identifies managerial, financial, and technological causes for the lack of adoption. [9; 18; 33; 41].

\section{SELECTION OF LIKELY ANTECEDENTS OF RFID ADOPTION}

After an extensive review of the literature, four main categories of adoption variables were identified: adoption based on characteristics of (i) the innovation, (ii) the individual, (iii) the adopting organization, and (iv) the environment. A fifth category, financial characteristics, was added to the analysis because uncertainty about the value or ROI of RFID adoption has been regularly cited by nonadopters as a primary factor in their decision not to invest in RFID [13; 18; 21].

Once the categories of adoption antecedents were identified, it was necessary to develop a process to evaluate each category and to identify those specific variables within each category that should be included in a model of likely antecedents of RFID adoption. The selection of antecedents was based on two primary factors: (i) the likelihood of those antecedents being good predictors and (ii) a presence of sufficient relevant literature to justify their selection and mapping to adoption of the specific technology of RFID in the context of the supply chain. Each of the four categories will now be evaluated using these two criteria and relevant adoption variables identified.

\section{Adoption Category 1: Innovation Characteristics}

These are features of an innovation that make it less or more desirable (by individuals), such as its complexity, compatibility, relative advantage afforded in its adoption, the ability to try it out, and the ability to explore the innovation. These five characteristics are explicitly explored by Rogers in his Diffusion of Innovation Theory [31]. Shown in Figure 2. Roger's model was validated in a significant research article on Perceived Characteristics of Innovating [24]. The “+” and “-” signs indicate positive and negative influences respectively.

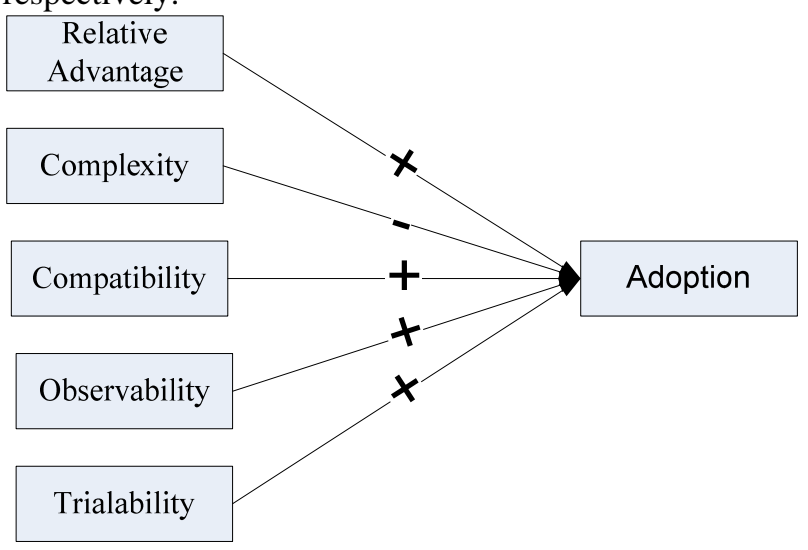

Figure 2: Reconstructed Roger’s Model [31]

Roger's model works well while comparing innovations on the basis of their innovation 
characteristics, which influence individual perceptions [17; 31]. characteristics if studied with the same population. However, RFID is not being examined in conjunction with another innovation in which the subjects (adopters) are the same population. Also, RFID adoption is being examined in context of the supply chain organization. Rogers' model (and its accompanying predictors) primarily affect individual adoption that is directly influenced by the innovation. Antecerents that are typically found significant in opganizitiepal adoption differl from those used on Rogers mødel.[1〉]. FAddeptioneasons, antecedents belonging to this category and Rogers' model will not be used for this study.

\section{Adoption Category 2: Individual Characteristics}

These are features and demographics of an individual that may influence their desire to use or adopt an innovation. This includes characteristics such as age, education, experience, attitudes and perceptions held by them. The renowned Technology Acceptance Models, (TAM)1 [7; 8] and its extension popularized as TAM 2 [38] examined innovation from an individual adoption perspective.

Figure 3 exemplifies how Roger's adoption model could be used to determine which DVD format (BluRay or HD-DVD) would be adopted by the mass market of consumers. A comparison such as this would bring out the differences in innovation

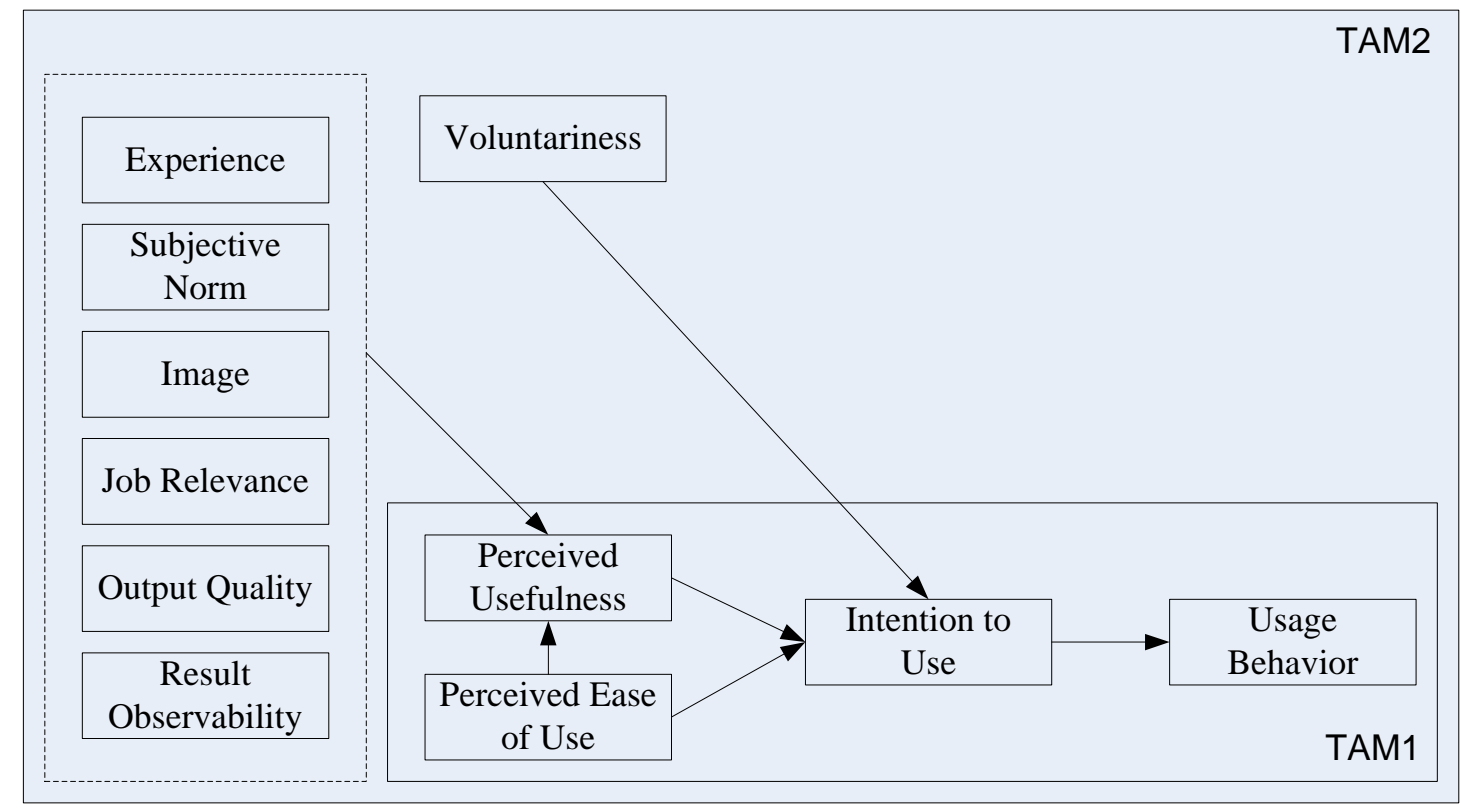

Figure 4: Reconstructed TAM1 \& TAM2 models [7; 38]

Two issues exist with the application of this model for the current study. First, user perceptions would affect organizational adoption only indirectly, as individual components influencing collective attitudes. Second, TAM1 was posited as a result of research conducted in 1988 - much before the technological revolution [25; 26], or the digital revolution, [3] in the last decade of the twentieth century changed the prevalent system of values towards information technology in general [3; 4; 35]. 
This lessens the validity of the model under current techno-economic [26] conditions. Finally, marquee organizational adoption studies $[6 ; 28 ; 37]$ have excluded these characteristics because of the personal nature of the characteristics. The current study will also not use these characteristics in this model.

\section{Adoption Category 3: Organizational Characteristics}

These are features, such as management characteristics and strategic initiatives, that describe or are pertinent to organizations. Further, there are factors within organizational adoption, such as leadership or financial considerations, that significantly differentiate the adoption setting from other categories. Frequently studied antecedents in this category include top management support, size of the organization, professionalism of the Information Systems (IS) unit, formal structure of the organization, return on investment and culture of the organization. Understandably, this group of characteristics contains several important factors that have been studied frequently and regularly found to be successful predictors of technology adoption. The organizational variables most often related to technology adoption have been top management support (tSUP), organizational size (oSIZE), and expected Return on Investment (eROI).

Top management support is one of the most well known antecedents of organizational adoption of IT. Top management support and cost justification have been found to be critical in IT implementation in Material Requirements Planning (MRP) industry [6]. Their primary contribution suggests "appropriate positioning of managerial rationality" in IT implementation research. Further, adoption of new technologies in small businesses [12; 27; 28], and in the supply chain [27] clearly demonstrated that top management support, organizational size and a costbenefit justification were significant antecedents of adoption. Two studies [20; 40] focused on workforce size. According to the one of these studies one [40] "the number of employees is by far the most common measure of organizational size”. An adoption study of internet based e-commerce adoption and migration at the firm level [14], confirmed the importance of the organizational antecedents and identified that a cost-benefit justification is one of the most significant of the three. Expected Return on Investment (eROI), essentially a cost-benefit analysis factor, has also been examined as an organizational characteristic. For instance, consider the loss of business (and profit) of not investing in RFID when a retail customer, such as Walmart, who is responsible for more than half of one's business leverages their power to mandate palette level RFID tagging [36]. One study examined practices with logistics IT systems and found tSUP, oSIZE \& eROI to be significant in context of adoption of EDI in logistics and supply chain organizations [5], finalizing their candidacy as good antecedents for this study.

\section{Adoption Category 4: Environmental Characteristics}

These are properties external to the organization, such as external pressure, external sources of information, and other forces outside of one's firm such as the government and relevant regulations [17]. External circumstances or conditions have been known to play a very significant role in adoption research, especially in the case of organizations. For instance, external pressure was acknowledged as an important characteristic to study and found significant in several others [28], expressed as competitive pressure [5; 27]. A study on e-commerce adoption suggested that external pressure was exerted by trading partners, especially when the firm was dependent on the partner. Another seminal study on EDI adoption [15] provides an example of an unnamed wholesaler of fresh food and vegetables succumbing to external pressure. He quotes the example of an unnamed firm with 110 employees and sales of $\$ 18.5$ million, with no Information Systems (IS) staff, who sees little advantage to EDI adoption. However, the wholesaler agrees to make the firm EDI capable in order to maintain the $20 \%$ of sales he gets from the firms largest customer - the government. External Pressure therefore is a good antecedent to investigate for its ability to predict the adoption of RFID.

\section{SUMMARY}

While the RFID technology has been around for several decades, its prospects for application in the supply chain are far more recent. It provides benefits such as elimination of the need for line of sight [22], authentication, location [2], total asset visibility [34], in-transit visibility [19], and containment [32]. These new capabilities bring new benefits. Pitted against these benefits are challenges. The foremost of these challenges are evolving standards, costs, concerns of privacy, and technological challenges that are inherent to the RFID technology [10;22]. Benefits and challenges act as driving forces and impediments respectively to the phenomenon of adoption, making this a rich area for research 
A review of literature on adoption of new technology by organizations reveals some of the best predictors of IT adoption by organization to be: Top Management Support (tSUP), External Pressure (ePRESS), Organizational Size (oSIZE), and Expected Return on Investment (eROI). Since the innovation of RFID technology is a current phenomenon as of writing of this paper, there has been little empirical research to confirm these antecedents of adoption with respect to RFID. Therefore, this study examines the above mentioned antecedents of organizational adoption of IT innovations for the RFID technology. The proposed model for investigation is shown below.

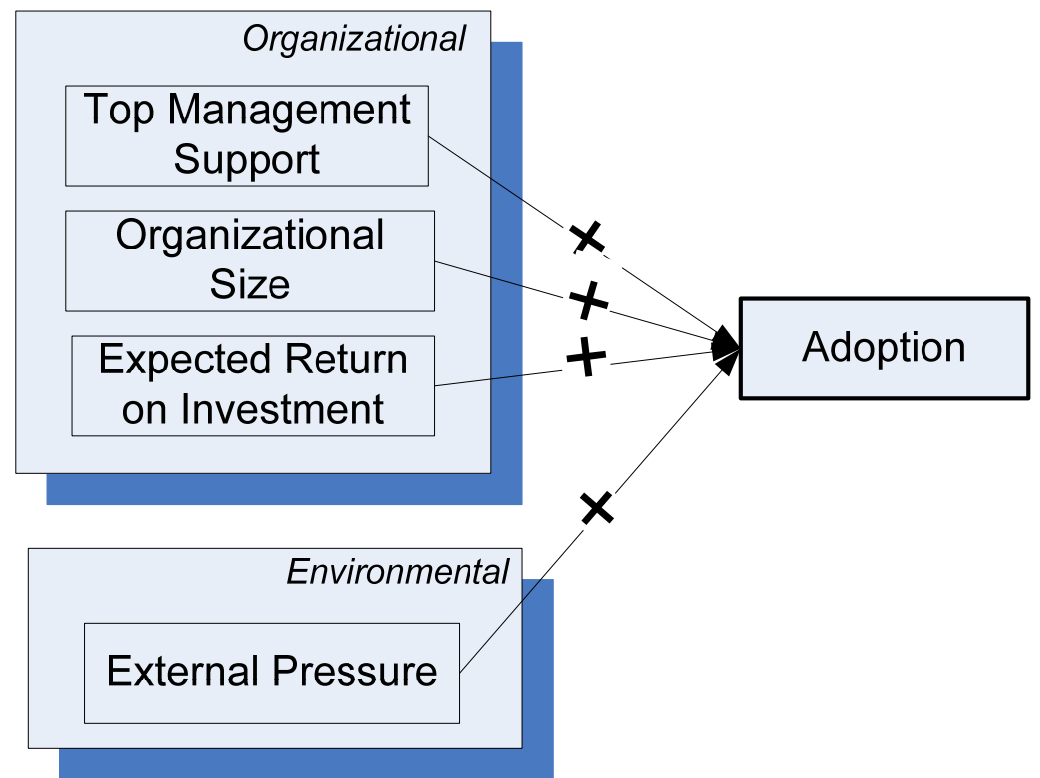

Figure 5: Proposed Model for RFID Adoption

\section{REFERENCES}

1. Ajzen, I., \& Fishbein, M. (1974). Factors influencing intentions and the intention-behavior relation. Human Relations, 27(1), 1-15.

2. Asif, Z., \& Mandviwalla, M. (2005). Integrating the supply chain with RFID: A technical and business analysis. Communications of the AIS, 2005(15), 393-426.

3. Barnatt, C. (2001). The second digital revolution. Journal of General Management, 27(2), 1-16.

4. Boas, T., Dunning, T., \& Bussell, J. (2005). Will the digital revolution revolutionize development? Drawing together the debate. Studies in Comparative International Development, 40(2), 95-110.

5. Closs, D. J., \& Xu, K. (2000). Logistics information technology practice in manufacturing and merchandising firms: An international benchmarking study versus world class logistics firms. International Journal of Physical Distribution \& Logistics Management, 30(10), 869-886.

6. Cooper, R. B., \& Zmud, R. W. (1990). Information technology implementation research: A technological diffusion approach. Management Science, 36(2), 123-139.

7. Davis, F. D. (1989). Perceived usefulness, perceived ease of use, and user acceptance of information technology. MIS Quarterly, 13(3), 318-340.

8. Davis, F. D., Bagozzi, R. P., \& Warshaw, P. R. (1989). User acceptance of computer technology: A comparison of two theoretical models. Management Science, 35(8), 982-1003.

9. Ferguson, R. B. (2007). RFID adoption is lagging. eWeek, 24, 25-25.

10. Forcini, H. (2004). Successfully deploying RFID, managing automation (Vol. 2005).

11. Fulcher, J. (2005). Honda sets a higher standard for EDI compliance. Manufacturing Business Technology, 23, 1.

12. Grandon, E. E., \& Pearson, J. M. (2004). Electronic commerce adoption: An empirical study of small and medium us businesses. Information \& Management, 42(1), 197-217.

13. Hoffman, W. (2005). When will RFID deliver ROI? Pacific Shipprer, 118-119.

14. Hong, W., \& Zhu, K. (2006). Migrating to internet-based e-commerce: Factors affecting ecommerce adoption and migration at the firm 
level. Information \& Management, 43(2), 204222.

15. Iacovou, C. L., Benbasat, I., \& Dexter, A. S. (1995). Electronic data interchange and small organizations: Adoption and impact of technology. MIS Quarterly, 19(4), 465-485.

16. Iacovou, C. L., Izak, B., \& Dexter, A. S. (1995). Electronic data interchange and small organizations: Adoption and impact of technology. MIS Quarterly, 19(4), 465.

17. Jeyaraj, A., Rottman, J. W., \& Lacity, M. C. (2006). A review of the predictors, linkages, and biases in it innovation adoption research. Journal of Information Technology, 21(1), 1-23.

18. Katz, J. (2006). Reaching for ROI on RFID. Industry Week, 255(2), 29-30.

19. Kolleda, D. (2005). Achieving in-transit visibility (ITV): A study of technology on ITV in the department of defense: U.S. Army War College, Carlisle Barracks, Carlisle, PA, 17013-5050.

20. Lee, G., \& Xia, W. (2006). Organizational size and it innovation adoption: A meta-analysis. Information and Management, 43(8), p975-985.

21. Liss, D. (2002). Calculate your ROI, make two envelopes., 2006, from http://www.gantthead.com/article.cfm?ID=9641 8

22. Lundstrom, S. (2004). The bottom line: Rfid will have a dramatic impact on the operation of global supply chains over the next 10 years: AMR Research.

23. Matta, V., \& Moberg, C. (2006). The development of research agenda for RFID adoption and effectiveness in supply chains. Issues in Information Systems, 7(2), 246-251.

24. Moore, G. C., \& Benbasat, I. (1991). Development of an instrument to measure the perceptions of adopting an information technology innovation. Information Systems Research, 2(3), 192-222.

25. Pérez, C. (2003). Technological revolutions and financial capital: The dynamics of bubbles and golden ages: Edward Elgar Pub.

26. Pérez, C. (2004). The new techno-economic paradigm. Paper presented at the High Level Conference "Looking into the future of Information and Communication Technologies", Amsterdam, Netherlands.

27. Power, D., \& Simon, A. (2004). Adoption and diffusion in technology implementation: A supply chain study. International Journal of Operations \& Production Management, 24(6), 566-588.

28. Premkumar, G., \& Roberts, M. (1999). Adoption of new information technologies in rural small businesses. Omega, 27(4), 467-485.
29. Roadcap, C. A., Smith, P. M., \& Vlosky, R. P. (2000). EDI and barcoding in the homecenter industry: 1992 vs. 1998. Forest Products Journal, 50(9), 32-39.

30. Roberts, B. (2007). How to cash in on the highdefinition dvd format war. Electronic News (10616624), 53(7), 30.

31. Rogers, E. (2003). Diffusion of innovations: Free Press.

32. Römer, K., Schoch, T., Mattern, F., \& Dübendorfer, T. (2004). Smart identification frameworks for ubiquitous computing applications. Wireless Networks, 10(6), 689-700.

33. Seewald, N. (2006). Evolving standards boost adoption. Chemical Week, 168, 21-21.

34. Snider, J. R. (2001). Army's approach to interoperability. Paper presented at the Naval Interoperability Workshop.

35. Sterling, B. (1997). The digital revolution in retrospect. Communications of the ACM, 40(2), 79.

36. Sullivan, L. (2004). Walmart's way. InformationWeek, 36-50.

37. Swanson, E. B. (1994). Information systems innovation among organizations. Management Science, 40(9), 1069-1092.

38. Venkatesh, V., \& Davis, F. D. (2000). A theoretical extension of the technology acceptance model: Four longitudinal field studies. Management Science, 46(2), 186-205.

39. Walton, L. W. (1994). Electronic data interchange (EDI): A study of its usage and adoption within marketing and logistics channels. Transportation Journal, 34(1), 37-46.

40. Yao, J. E., Xiaohe, X., Chang, L., \& Lu, J. (2002). Organizational size: A significant predictor of it innovation adoption. Journal of Computer Information Systems, 43(2), 76-82.

41. Young, D. (2006). RFID implementation not moving fast enough, FDA says. American Journal of Health-System Pharmacy, 63(6), 500502. 